\title{
Un caso atípico de tos y estornudos
}

\author{
An atypical case of cough and sneezes
}

\section{CASE REPORT}

A 68-year old male with prior hypertension and hypertensive nephrosclerosis was admitted in the emergency department after a fully recovered transient episode of loss of consciousness of about 1 minute. He referred a fit of sneezing before losing consciousness and there was no evidence of seizures, chest pain, shortness of breath or palpitations. Clinical examination including neurological exam was normal and there was no evidence of postural hypotension. Further cardiologic evaluation for syncope, including electrocardiogram, echocardiogram and cardiac monitoring, was normal. A more detailed story revealed that the patient had recurrent headaches for at least 6 years, triggered by coughing and sneezing with spontaneous recover after a few minutes. A computed tomography scan of the brain was performed reveling a large extra axial lesion in the left fronto-temporo-parietal region, suggestive of an arachnoid cyst with shift of the median structures, confirmed by magnetic resonance imaging (Figures 1 to 4). The patient refused resection of the cyst and is under periodic surveillance imaging. Headaches and syncope might be explained by the disruption of Monro-Kellie's theory: there is an additional and transient increase in intracranial pressure provoked by Valsalva maneuvers in a patient with a large cyst that also causes obstruction to normal cerebrospinal fluid and blood flow dynamics. Valsalva triggered symptoms are rarely reported as the first presentation of intracranial neoplasms and a high index of suspicion is required to achieve the correct diagnosis. Patients with non-cardiac syncope and cough-headache should be evaluated for an intracranial le$\sin ^{1,2}$.

\section{REFERENCES}

1. Lane RJ, Davies PT. Modified Valsalva test differentiates primary from secondary cough headache. J Headache Pain. 2013;14(1):31

2. Maznyczka A, Squire IB. Cough syncope-a diagnosis under pressure [published correction appears in Lancet. 2010 Sep 18;376(9745):958. Maczyczka, Annette [corrected to Maznyczka, Annette]]. Lancet. 2010;376(9739):486.

Palabras clave: quistes aracnoideos, presión intracraneal, teoría de Monro-Kellie.

Keywords: arachnoid cysts, intracranial pressure Monro-Kellie's theory.
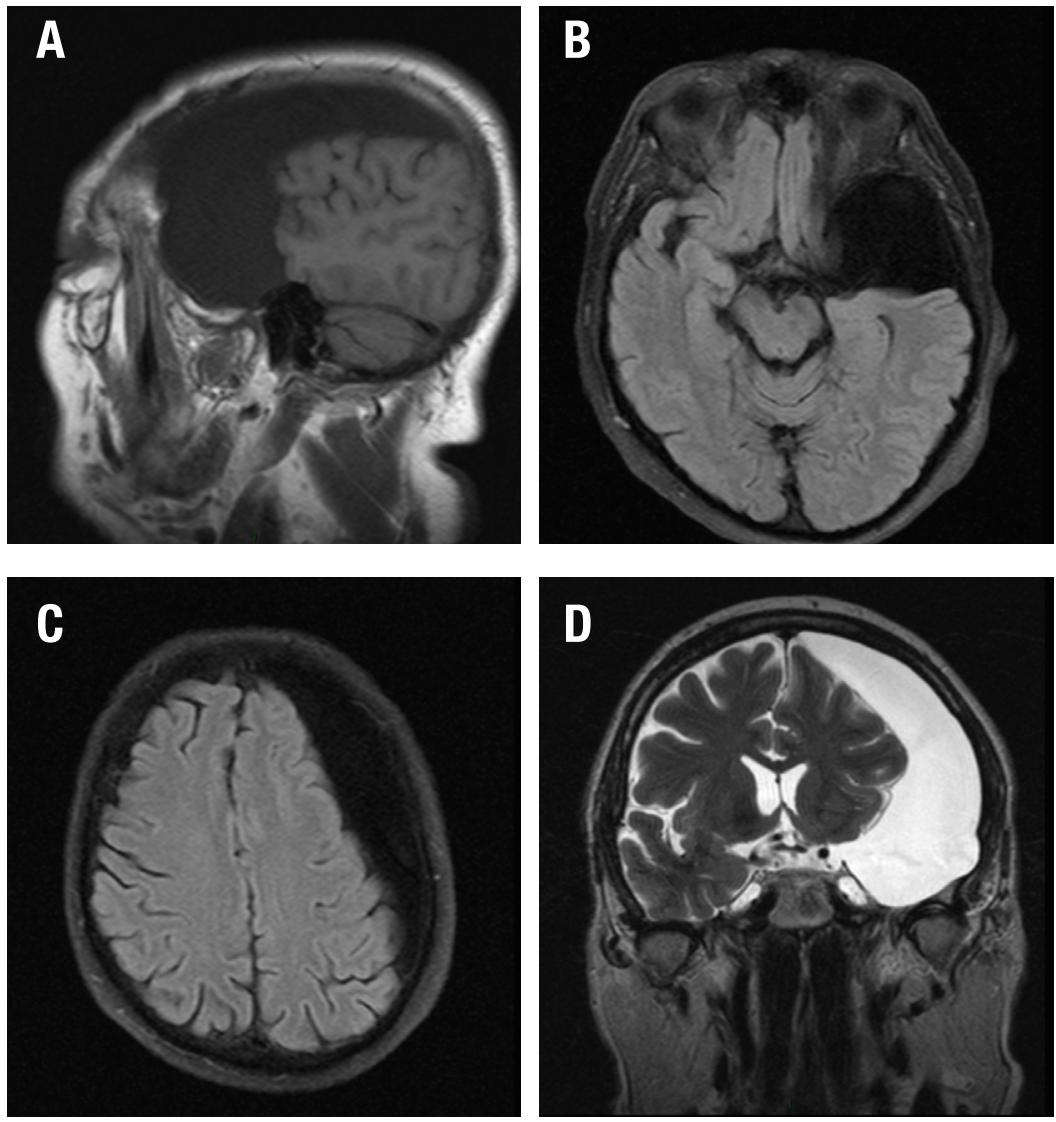

Fig. 1 Brain MRI showing left-sided fronto-temporo-parietal extra-axial cyst with cerebrospinal fluid intensity. A: T1-weighted sagital view. B and C: T2 TIRM dark fluid transverse views. D: T2-weighted coronal view

Fani Ribeiro ${ }^{1}$, Sara Pinto ${ }^{1}$

${ }^{1}$ Medicina Interna. Centro Hospitalar do Baixo Vouga, Aveiro. Portugal.

Correspondencia:fanisusana87@gmail.com

Cómo citar este artículo: Ribeiro F, Pinto S

Un caso atíico de tos y estornudos. Galicia Clin 2021; 82-1: 56

Recibido: 13/9/2019; Aceptado: 21/10/2019 // https://doi.org/10.22546/60/2080 